\title{
Herder: uma proposta de reforma radical na educação
}

\author{
Herder: a proposal of radical reform in education
}

\author{
Marcos Fábio Alexandre Nicolau \\ marcosmcj@yahoo.com.br \\ (Universidade Estadual Vale do Acaraú, Ceará, Brasil)
}

Resumo: Este artigo investiga, sob uma perspectiva pedagógico-filosófica, a pro posta de "formação da humanidade" nos escritos de J. G. Herder. Pretendo analisar sua proposta de reforma no ensino, cuja radicalidade constitui um marco para o sistema educacional alemão, sendo implantada por Herder em sua passagem como conselheiro do ducado de Weimar. Severo crítico das Luzes, Herder pretendeu conciliar a racionalidade científico-filosófica ao sentimento e à paixão, próprios da literatura oitocentis ta alemã, forjando uma ideia de formação (Bildung) que, além de trazer em si a racionalidade e a sapiência, constitui-se também de emoção, criatividade, cultura e história.

Palavras-chave: Bildung; Educação alemã; humanidade.
Abstract: This paper investigates, from a pedagogical and philosophical perspective, the proposal of "humankind formation" in the writings of J. G. Herder. I intend to analyze his proposal for educational reform, whose radicalism is a milestone for the German educational system, being implemented by Herder in his passage as adviser of the dukedom of Weimar. Severe critic of the Enlightenment, Herder intended to reconcile the scientifical and philosophical rationality to the feeling and the passion, which are nature of the nineteenth-century German literature, forging an idea of formation (Bildung) that besides to bring rationality and wisdom in itself, is also constituted by emotion, creativity, culture and history.

Keywords: Bildung; German education; humankind.

DOI: http://dx.doi.org/10.11606/issn.2318-9800.v19i2p83-94

A formação de J. G. Herder inicia-se após sua chegada, aos dezoito anos, a Könisberg, onde dois espíritos iam influir decisivamente sobre ele: primeiramente I. Kant, então ainda privatdozent da Universidade local, que subministrou ao jovem estudante de teologia as primeiras 
ideias filosóficas básicas e o conhecimento tanto dos empiristas ingleses como de Rousseau ${ }_{i}$ e J. G. Hamann, por quem se sentiu mais atraído, talvez devido a uma primogênita afinidade de espírito. Hamann, o "mago do norte", acabava de apresentar à comunidade acadêmica alemã sua Aesthetica in nuce (1762), umas das obras fundamentais do Sturm und Drang (Tempestade e Ímpeto). O resultado desses encontros fora que, ainda em Könisberg, iniciara sua carreira docente, em 1763, no Colégio Fredericiano, experiência que rememora mais tarde por proporcionar-lhe um maior desenvolvimento de suas ideias pedagógicas, além do esclarecimento conceitual das mesmas. ${ }^{1}$

Cabe salientar que Herder venerou com amor idolátrico até sua morte o "mago do norte", de cuja estranha capacidade de atração falam todos os seus contemporâneos. ${ }^{2}$ Assim, não é de se admirar que tenha sido o próprio Hamann quem recomendou Herder como colaborador para a escola catedrática de Riga, na Livonia. Na ocasião enviara ao reitor da instituição uma carta de recomendações onde discorre sobre as virtudes acadêmicas do jovem Herder, então com vinte anos, mas possuidor de:

uma respeitável quantidade de conhecimentos históricos, filosóficos e estéticos, e com um grande desejo de cultivar-se o mais promissor

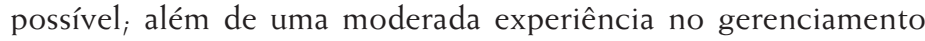
escolar. $^{3}$

Aqui, em suas funções de predicador e de pedagogo, pronto ganhou influência e popularidade na sociedade de Riga, de forma que tentaram manter-lhe ali com todos os meios. Porém, reter um homem que sonha a si mesmo para além do mundo dos livros, e se vê como reformador da humanidade, não é uma fácil tarefa. Herder fora um espírito impulsionado à realidade e à ação, motivo pelo qual pediu demissão de seu cargo para realizar uma jornada pela França com um amigo. Tal viagem, no entanto, não fora sem propósito, Herder a usaria para familiarizar-se com as melhores instituições de educação e ensino na França, na Holanda, na Inglaterra e na Alemanha, e, ao

1. Ver RAUMER, K. von. Johann Gottfried Herder. The American Journal of Education, Londres, v.VI, n. XVI, Mar. 1859, pp. 195-196.

2. Ver GEROLD, K. G. Johann Gottfried Herder. In: Jobann Gottfried Herder 1803/1978. Bonn; Bad Godesberg: Inter Nationes, 1978, p. 8.

3. HAMANN, J. G. apud RAUMER, K. von. Jobann Gottfried Herder, p. 196. 
retornar a Riga, fundaria uma instituição educacional. ${ }^{4} \mathrm{O}$ resultado dessa expedição pedagógica fora o Diário da minha viagem no ano de 1769 (Journal meiner Reise im Jabr 1769), no qual dispôs seus ideais pedagógicos, propondo-se uma leitura, uma análise e uma nacionalização das diversas teorias pedagógicas de seu tempo (como as de Locke e Rousseau, dentre outras) incorrendo necessariamente em uma proposta de reforma escolar.

Como principal objetivo, Herder propunha um currículo mais realista e pragmático, a partir de um método para "formar espíritos práticos, porque se ensinam palavras; preferencialmente, ao contrário, meu método ensinará coisas". ${ }^{5}$ Sua crítica à tirania exercida pela língua latina se reverterá em uma das mais agudas defesas da língua alemã, que nesse período ainda lutava por seu espaço literário. Sua defesa das escolas reais (Realschuler) demonstra seu compromisso com uma educação antiescolástica e, acima de tudo, menos iluminista, em sua proposta francesa de um esclarecimento como solução. Todo Aufklärer estava preparado para aceitar uma dissociação entre intelecto e emoção como preço do progresso, como se pode notar em Kant. Para Herder, no entanto, de nada valeria um esclarecimento que ameaçasse nossa própria natureza, essencialmente constituída de um lado racional e de um lado afetivo, que não poderia em hipótese alguma ser descartado. ${ }^{6}$ Com tais ideais, altamente radicais frente às propostas de reformas do período, Herder encontrou notoriedade no cenário educacional alemão, e quando viu a oportunidade de agir de forma mais efetiva sobre a realidade escolar, o fez: após uma curta estadia como professor na Universidade de Göttingen (1775), aceita, em 1776, o convite de Goethe, então conselheiro do Duque de Weimar, Karl August (1757-

4. Ver Idem, p. 199. Esse período lhe serviu para, por exemplo, reler o Emílio de Rousseau, e conhecer melhor as propostas de Basedow e Pestalozzi. Ainda sobre essas influências ver a importante obra de ANDRESS, J. M. Jobann Gottfried Herder as an educator. New York: G. E. Stechert \& Co., 1916, pp. 21-22.

5. HERDER, J. G. apud RAUMER, K. von. Jobann Gottfried Herder, p. 197.

6. Ver MOORE, G. Introduction. In: HERDER, J. G. Selected writings on aesthetics. Edição e tradução de Gregory Moore. Princeton: Princeton University Press, 2006, p. 3. 
1828), para o cargo de conselheiro do alto consistório do Ducado de Weimar - cargo que vai exercer por cerca de 25 anos. $^{7}$

Seus cargos diretivos permitiram-lhe, em Weimar, atuar decisivamente, inclusive no terreno prático, na estruturação do sistema educativo, uma tarefa à qual se entregou - apesar da sobrecarga de outras obrigações - com máximo sentido de responsabilidade. Com seu plano escolar de 1783, preocupou-se em fornecer uma melhor formação e remuneração dos mestres, o que culminou com a fundação de um seminário para a formação de professores, em 1787, no qual nota-se a forte influência da pedagogia de Pestalozzi na formação dos mestres. Realizou uma reforma escolar radical em Weimar, que na época chegou a ser conhecida como a Atenas da Alemanba, pela concentração de intelectuais que o duque, contando com a influência de Goethe, conseguiu reunir. Outro ponto de grande importância na proposta de reforma herderiana ocorrera no Gymnasium de Weimar, no qual fomentou as ideias neo-humanistas, dotando seu currículo de novos ideais e métodos nos estudos clássicos, enfatizando principalmente o estudo da língua grega. Esses métodos e ideais inspiraram um novo tipo de gymnasium na Alemanha ${ }^{8}$ - que fora assumido, por exemplo, por Humboldt.

A influência de Herder no campo educacional alcançou assim forte reconhecimento. Suas ações não foram dissociadas de uma constante e intensa produção de escritos de teor pedagógico. Seus escritos sobre o tema da educação chegam ao considerável número de 30 volumes, que somam em torno de 600 páginas. ${ }^{9}$

Não por acaso outros Estados alemães recorreram a ele, como sendo uma reconhecida eminência no campo do ensino, fama que ele mesmo tratara de justificar:

Aos dezenove anos comecei a lecionar uma classe superior de uma instituição acadêmica, e desde esse tempo nunca negligenciei as responsabilidades de um professor, ou mesmo de um oficial escolar. Tenho consultado países estrangeiros, alguns católicos até, em re-

7. BOSSERT, A. Goethe. Ses précurseurs et ses contemporains: Klopstock, Lessing, Herder, Wieland, Lavater / La jeunesse de Goethe. $12^{\mathrm{a}}$ ed. Paris: Librarie Hachette, 1882, p. 112.

8. Ver ANDRESS, J. M. Johann Gottfried Herder as an educator, pp. 100-104.

9. Ver Idem, p. 5. 
lação a suas organizações escolares; e, sem descuidar de uma grande modéstia, acredito poder afirmar que compreendo do assunto. ${ }^{10}$

Não só por isso Herder surge como uma das figuras mais eminentes do cenário cultural alemão da passagem do século XVIII ao XIX, sua notoriedade também se deu por propor a noção de que um povo (Volk) ${ }^{11}$ caracteriza-se culturalmente como um produto da linguagem, do clima, e da experiência, sem as quais possuiria-se apenas "uma palavra", ou seja, uma compreensão meramente subjetiva da realidade histórico-social dos homens. ${ }^{12}$ Suas Ideias para a filosofia da bistória da bumanidade (Ideen zur Philosophie der Geschichte der Menschheit), com redação entre 1784 e 1791, de certa forma caracterizam uma síntese do século XVIII e, no entanto, marcam uma mudança significativa em relação a perspectiva do iluminismo racionalista padrão de até então, pois, como bem explicita no texto abaixo, Herder é um dos principais críticos do movimento iluminista:

Não haverá ninguém no mundo capaz de compreender que a luz não alimenta os homens? Que a quietude, a opulência e a chamada liberdade de pensamento nunca poderão constituir a felicidade e a determinação gerais? ${ }^{13}$

10. HERDER, J. G. apud RAUMER, K. von. Jobann Gottfried Herder, pp. 202.

11. Devemos a Herder o descobrimento do "povo", não como estrato social, mas como um organismo vivo que inclui todas as individualidades. A história se converteu para ele na "marcha de Deus através das nações". Este processo de alienação dos alemães com respeito a seu próprio ser havia começado especialmente graças a aceitação, frequentemente lamentada por Herder, da língua latina e logo à imitação incondicional dos modelos franceses e gregos. Para deter aquele processo no último momento, Herder pediu sempre uma volta às raízes de seu próprio povo, não no sentido de uma restauração que teria contradito sua visão histórica, senão como uma reflexão sobre nossa maneira de ser essencial pré-formada, sobre aquele "modo de pensar nacional" cujo desenvolvimento orgânico posterior considerava ele como a tarefa mais importante, ver GEROLD, K. G. Jobann Gottfried Herder, p. 22.

12. HERDER, J. G. Também uma filosofia da bistória para a formação da bumanidade. Tradução portuguesa de Jose M. Justo. Lisboa: Edições Antígona, 1995, p. 35 .

13. Idem, p. 59 . 
Esse pequeno trecho da obra Também uma filosofia da bistória para a formação da bumanidade (Aucb eine Pbilosopbie der Geschicbte zur Bildung der Menschbeit) ${ }^{14}$, de 1774 , demonstra o poder crítico do autor, que viria a influenciar diretamente o contraprojeto esboçado pelo movimento do Sturm und Drang, assim como o do romantismo alemão, ao propor o sentimento, e não apenas a razão, como o ideal a ser buscado para formação (Bildung) ${ }^{15}$ dos indivíduos. Não por acaso, baseiam-se nele os historiadores e filósofos, os admiradores do orgânico e do universal, pois Herder concede lugar a todas as ciências no edifício da humanidade e, não por acaso, os pedagogos o veneram como um dos maiores educadores. ${ }^{16}$

Herder quer transmitir a herança da história às gerações vindouras. Seu olhar dirige-se sempre das eras passadas às futuras. Importante é, para ele, a plataforma histórica e o ideal do porvir da gênese das novas gerações. Vive em própria pessoa o que defende em seus escritos, a saber: o progresso da humanidade: "A repugnância dos que vêm

14. É interessante notar que diferentemente de Lessing, que traz no título de sua obra o termo Erziebung, Herder usa o termo Bildung, para expressar a ideia de educação, compreendendo ambos, nos dois termos, o mesmo significado, o que não se manterá assim, tomando cada termo um sentido específico no contexto pedagógico alemão. Outra curiosidade é o "Auche Eine", onde o autor não está se referindo a Lessing, mas as obras de Isaak Iselin e de Voltaire. Sobre o assunto ver HODGSON, P. C. God's wisdom: Toward a theology of education. Louisville: Westminster John Knox Press, 1999, p. 40.

15. À primeira vista, a morfologia bastante simples da palavra Bildung poderia sugerir uma nitidez semântica em seu uso que, de fato, está bem longe de ser verdadeira. Bild, em geral, significa contorno, imagem ou, mais precisamente, forma - e o prefixo "-ung" assinala o processo segundo o qual essa forma seria obtida, o que nos permitiria traduzi-la em português por formação sempre em itálico no decorrer do artigo -, o que justifica minha opção no decorrer do texto, embora o conceito possua uma complexidade em sua tradução. Conferir em BRITTO, F. de L. Sobre o conceito de educação (Bildung) na filosofia moderna alemã. Educação On-line, Rio de Janeiro, n. 6, 2010. Disponível em <http://www.maxwell.lambda.ele.puc-rio.br/rev_edu_ online.php?strSecao=input0>. Acesso em 29 mar. 2014.

16. O que deve ser algo a ser reconhecido ainda, já que certas coletâneas de historia da educação sequer citam Herder, algo que fora reivindicado já por ANDRESS, J. M. Jobann Gottfried Herder as an educator, pp. 2-4. 
depois só mostra que houve desenvolvimento, progressão, que se foram subindo os degraus da escada". ${ }^{17}$

A humanidade é apreciada como a melhor entre as organizações da natureza. Ela é o âmago do cosmo de Herder. Tudo que revele qualquer conexão com a humanidade, Herder o procura entusiasticamente para apresentar ao homem o grande espelho de sua história e para educar a si mesmo, ou seja, cabe educar o gênero humano para que chegue à plena humanidade. Eis o sentido da história humana em Herder.

Humanidade significa em Herder, em ultima análise, interiorização, significa ter caráter, síntese do ideal por ele buscado:

Quisera poder resumir na palavra humanidade tudo o que tenho dito até agora sobre a nobre formação do homem para a razão e a liberdade, os sentidos e impulsos refinados e uma saúde delicada forte e para completar e dominar a terra ${ }_{i}$ pois o homem não tem palavra mais nobre para sua determinação que o que ele mesmo é: aquele no qual vive impressa a imagem do Criador de nosso mundo, tal como pode fazer-se visível aqui. Para desenvolver suas obrigações mais nobres não temos que desenhar sua imagem. ${ }^{18}$

Nessa perspectiva o mais íntimo que vivifica a humanidade é a educação da razão e do sentimento. Mas ambos, razão e sentimento, devem carinhosa e confiantemente aceitar-se, devem complementar-se para que sirvam também de deleite e prazer estético. Herder não crítica o fracasso da educação da humanidade - contenta-se com o "quase-perfeito", porque o humano não comporta o perfeito e a debilidade do humano é evidente:

O essencial em nossa vida não é nunca possessão, senão sempre progressão; não temos sido homens até que tenhamos vivido até o final ${ }_{i}$ por sua vez, a abelha foi abelha desde que construiu sua primeira célula. ${ }^{19}$

17. HERDER, J. G. Também uma filosofia da bistória para a formação da bumanidade, p. 20.

18. HERDER, J. G. Outlines of a philosopby of the bistory of man - In Two Volumes. $2^{\text {a }}$ ed. Tradução de T. Churchill. Londres: Luke Hansard for J. Johnson, 1803, p. 173.

19. HERDER, J. G. Ensayo Sobre el Origen del Lenguaje. In: Obra Selecta. Tradução espanhola de Pedro Ribas. Madrid, Alfaguara, 1982, p. 146. 
Dentre suas reflexões, Herder criticara asperamente as condições em que se encontra o sistema educacional de seu país, na época descentralizado, fragmentado e, principalmente, distanciado de uma efetiva formação do povo alemão:

Para tanto aí estão os mercados resplandecentes destinados a formação da humanidade, os púlpitos e palcos, salas de audiências, bibliotecas, escolas e, muito em especial, coroação de todos estes lugares, as ilustres academias! Que luminosidade! Para a glória eterna dos príncipes! Para quão grandes desígnios de formação, de difusão das luzes no mundo, de felicidade da humanidade! Inauguradas com esplendor... E para quê? Que fazem elas? Que podem fazer? Jogam! ${ }^{20}$

Contra esse sistema, bastante influenciado pelo ideal iluminista francês, sua proposta será a de efetivar uma formação da humanidade, conceito pelo qual busca dar um novo ardor ao projeto educacional alemão: propõe a formação de uma humanidade-nação, que só pode ser afirmada com um novo projeto de formação, ou seja, como uma reforma do sistema escolar, sendo Herder plenamente consciente da complexidade do projeto:

Este livro, este autor, esta quantidade de obras deve formar. O resultado destes esforços, a filosofia do nosso século, deve formar. E que outra coisa pode querer isto dizer senão fazer despertar e fortalecer as inclinações que podem tornar feliz a humanidade? E que abismo é preciso transpor para que tal aconteça! $!^{21}$

Tal proposta de reforma é fruto do amadurecimento de certas ideias analisadas pelo autor, como o mesmo confidencia em seu Diário, no qual propõe um completo projeto de reforma educacional. $\mathrm{O}$ projeto é o de "despertar a humanidade", ou seja, despertar "uma virtude, uma felicidade e uma energia", que Herder afirma serem superiores as que se podem recolher na história de $\operatorname{Iselin}^{22}$, porque resulta

20. HERDER, J. G. Também uma filosofia da bistória para a formação da bumanidade, p. 74 .

21. Idem, ibidem.

22. É o filósofo Isaak Iselin, que publica em 1764 uma obra intitulada "Sobre a história da humanidade" (Über die Geschicbte der Menschbeit), um dos primeiros a exortarem os seus contemporâneos a se lançarem numa investigação filo- 
"da representação viva das imagens de todas as épocas, costumes e povos". ${ }^{23}$ Plano grandioso, como bem nos informa Justo ${ }^{24}$, pois não falta a indicação minuciosa de um eclético conjunto de leituras a colecionar em uma publicação periódica preparatória, um anuário dos escritos úteis para a humanidade:

Obra importante! Que irá buscar a teologia e a homilética, a arte da interpretação e a moral, a história da Igreja e aos ascetas apenas aquilo que para a humanidade aí houver de imediato, para ajudar a esclarecê-la (aufklären), para a elevar a novas alturas, [...] para a mostrar debaixo de uma nova luz [...]. Para tanto servirão de apoio a história e o romance, a política e a filosofia, a poesia e a arte dramática, ${ }_{i}$, no que a estas últimas respeita, o ponto de vista principal [a adotar] não será esse [ou seja, o literário], mas uma perspectiva muito útil e formativa (bildend)! Uma tal publicação seria leitura para todos! Não a temos ainda, embora tenhamos já materiais para ela! Ao ensinar a tomar em atenção a fundamental perspectiva de uma humanidade que se forma, criaria na Alemanha uma era de formação (Bildung). ${ }^{25}$

Essa prenunciada "era de formação" só seria possível através da efetivação de um plano progressivo de formação da humanidade. Tal compreensão da história da humanidade é algo muito caro a Herder, que sintetiza em seus escritos tudo aquilo que os séculos anteriores

sófica da história da humanidade, dentre os quais o próprio Herder. Herder é crítico da postura assumida por Iselin, que tem correspondência a de Condorcet, defensora desse progressismo iluminista que cria ser a felicidade algo a ser alcançado ao final do desenvolvimento histórico. Para Herder, plenitude e felicidade já se encontram no individuo histórico. A perfeição ou consumação não estão no final da historia, senão "repartida" ao longo de todos os seus momentos, sendo cada etapa prefeita a sua maneira: "Cada um dos estádios contém em si mesmo o ponto central da sua felicidade" (HERDER, J. G. Também uma filosofia da bistória para a formação da bumanidade, p. 45). Sobre a relação Herder-Iselin, ver PELÁEZ, F. J. C. La filosofía de la bistoria de Johann G. Herder. Sevilha: Universidad de Sevilla, 2004, pp. 17-53.

23. HERDER, J. G. Journal meiner Reise im Jabr 1769. Historisch-kritische Ausgabe herausgegeben von Katharina Mommsen. Stuttgart: Philipp Reclam, 1976, p. 31 .

24. JUSTO, J. M. Posfácio. In: HERDER, J. G. Também uma filosofia da bistoria para a formação da bumanidade, p. 156.

25. HERDER, J. G. Journal meiner Reise im Jabr 1769, pp. 34-35. 
construíram em parcelas. Nessa apreensão do projeto da humanidade, como informa no Diário, sua experiência como bibliotecário assistente em Riga fora decisiva, dotando-lhe de uma universal educação, de modo que conheceu, a fundo, o pensamento germânico, francês e inglês. ${ }^{26}$

Para Herder, a formação era a totalidade das experiências que proporcionam uma identidade coerente e senso de destino comum para um povo. Em uma série de obras escritas ao longo de um período de quase cinquenta anos, Herder desenvolveu e defendeu a concepção de uma filosofia que está no coração da formação.

No que tange à filosofia, o pensador cobrava que a mesma proporcionasse um resultado prático, que poderia ser resumido como o crescimento humano, e que as ideias filosóficas têm que ser entendidas dentro de seu contexto social e histórico. Similar à renascença humanista, Herder acreditava que o principal objeto de estudo ao homem é o próprio homem, e, assim, buscava deslocar a filosofia acadêmica para uma antropologia filosófica.

Em sua perspectiva a filosofia é, pura e simplesmente, a teoria da formação, mais precisamente, a filosofia é a teoria de como o indivíduo se desenvolve em uma espécie de unidade orgânica, que irá trabalhar constantemente em direção ao pleno desenvolvimento dos seus talentos e habilidades, e irá impulsionar o progresso social ou formação social. A filosofia deve transformar os indivíduos e, no momento mesmo, ela deve ter um amplo impacto social.

Naturalmente também vige na pedagogia de Herder o objetivo da realização da humanidade, o que implica em uma didática que capte ao homem inteiro. Na planificação escolar descrita em seu Diário, previu para o desenvolvimento das forças da razão só a última etapa, pois a anterior devia dedicar-se a capacitar a fantasia, e a inicial a formação dos sentidos. Não através de definições, senão de um cheirar, ouvir e apalpar intensos devia captar a criança as coisas em seu entorno. ${ }^{27}$ Os esforços de Herder para construir uma educação sobre as condições específicas da psique infantil se relacionam com os de

26. BARNARD, F. M. J. G. Herder on Social \& Political Culture. Cambridge: Cambridge University Press, 2010, p. 64.

27. Idem, ibidem. 
Rousseau e Pestalozzi, encarnam assim uma tendência que até agora segue sendo a base de todas as reformas pedagógicas:

Não é verdade que na vida de cada homem há uma idade em que tudo se aprende pela inclinação, pela formação orientada pela autoridade, e em que nada se adquire pelo frio e seco exercício da razão? Uma idade em que as especulações, as reflexões sobre o bem, a verdade e o belo não conseguem penetrar os nossos ouvidos, reter nossa atenção, acordar o nosso espírito, e em que, pelo contrário, estamos inteiramente receptivos aquilo a que é costume chamar preconceitos e impressões inculcadas e despertadas pela educação? ${ }^{28}$

Essa experiência no campo educacional possibilitou a Herder a formulação de uma ideia própria de formação, já que o propósito iluminista de "formar a humanidade", universalmente e mediante "meia dúzia de ideias claríssimas", é parte integrante do mesmo pensamento político abstratizante contra o qual Herder encarniçadamente se manifesta. Assim, pode-se dizer que um aspecto preambular da ideia herderiana de "Bildung" é de natureza crítica de uma transformação da ideia de "educação", que terá uma influência tremenda no meio educacional alemão, fornecendo ao ideal de reforma educacional realizado no século XIX uma visão crítica que, ainda que não possa ser efetivada por questões políticas, estará presente tanto na proposta de reforma de Humboldt quanto na de Niethammer.

\section{Referências}

ANDRESS, J. Johann Gottfried Herder as an educator. New York: G. E. Stechert \& Co., 1916.

BARNARD, F. (Ed.) J. G. Herder on Social \& Political Culture. Cambridge: Cambridge University Press, 2010.

BOSSERT, A. Goethe. Ses précurseurs et ses contemporains: Klopstock, Lessing, Herder, Wieland, Lavater / La jeunesse de Goethe. $12^{\mathrm{a}}$ ed. Paris: Librarie Hachette, 1882.

BRITTO, F. Sobre o conceito de educação (Bildung) na filosofia moderna alemã. Educação On-line, Rio de Janeiro, n. 6, 2010. Disponível em $<$ http://www.maxwell.lambda.ele.puc-rio.br/rev_edu_online. php?strSecao=input0>. Acesso em 29 mar. 2014.

28. HERDER, J. G. Também uma filosofia da bistoria para a formação da bumanidade, pp. 12-13. 
GEROLD, K. G. Johann Gottfried Herder. Tradução de Eduardo Espert. In: Jobann Gottfried Herder 1803/1978. Bonn; Bad Godesberg: Inter Nationes, 1978.

HERDER, J. G. Outlines of a pbilosopby of the bistory of man - In Two Volumes. $2^{\text {a }}$ ed. Tradução de T. Churchill. Londres: Luke Hansard for J. Johnson, 1803.

Journal meiner Reise im Jabr 1769. Historisch-kritische Ausgabe herausgegeben von Katharina Mommsen. Stuttgart: Philipp Reclam, 1976.

Ensayo Sobre el Origen del Lenguaje. In: Obra Selecta. Tradução espanhola de Pedro Ribas. Madrid, Alfaguara, 1982, pp. 133-450

Abbandlung über den Ursprung der Sprache. In: Ulrich Gaier (Hg.). Jobann Gottfried Herder. Werke in zebn Bänden, Bd. 1, Frübe Scbriften 17641772. Frankfurt am Main: Deutscher Klassiker Verlag, 1985, pp. 695-810.

Ideen zur Pbilosopbie der Gescbicbte der Menscbbeit. In: Martin Bollacher (Hg.). Jobann Gottfried Herder. Werke in zebn Bänden, Bd. 6. Frankfurt am Main: Deutscher Klassiker Verlag, 1989.

Auch eine Pbilosopbie zur Gescbicbte der Bildung der Menscbbeit. In: Martin Bollacher (Hg.). Jobann Gottfried Herder. Werke in zebn Bänden, Bd. 4, Scbriften zu Pbilosopbie, Literatur, Kunst und Altertum. Frankfurt am Main: Deutscher Klassiker Verlag, 1994, pp. 9-108

Também uma filosofia da bistória para a formação da bumanidade. Tradução portuguesa de Jose M. Justo. Lisboa: Edições Antígona, 1995.

Selected writings on aesthetics. Edição e tradução de Gregory Moore. Princeton: Princeton University Press, 2006.

HODGSON, P. God's wisdom: Toward a theology of education. Louisville: Westminster John Knox Press, 1999.

JUSTO, J. Posfácio. In: HERDER, J. G. Também uma filosofia da bistoria para a formação da bumanidade. Lisboa: Edições Antígona, 1995, pp. 151-202.

PELÁEZ, F. J. C. La filosofía de la bistoria de Jobann G. Herder. Sevilha: Universidad de Sevilla, 2004.

RAUMER, K. Johann Gottfried Herder. The American Journal of Education, Londres: v. VI, nº XVI, Mar. 1859, pp. 195-208. 